\title{
A RESPONSIVE PARADIGM FOR TECHNOLOGY ENHANCED LEARNING (TEL) INTEGRATION INTO BUSINESS ORGANIZATIONS
}

\author{
Lina Kaminskiene][l.kaminskiene@pvt.vdu.lt],ElenaTrepule[e.trepule@smf.vdu.lt], \\ AušraRutkiene[a.rutkiene@smf.vdu.lt], Gintaras_Arbutavicius [g.arbutavicius@smf.vdu.lt], \\ Vytautas Magnus University, Lithuania
}

\begin{abstract}
The purpose of this paper is to explore the main barriers and enablers for integrating technology enhanced learning (TEL) into a business organization based on a responsive paradigm. The study is based on a current literature review on challenges and learners' needs for TEL and the preconditions for TEL curriculum integration into business organizations. The theoretical study is matched with a qualitative research on learners' needs for TEL in two international business organizations from IT sector. Technology enhanced learning (TEL) is tackling different barriers for learning in organizations. However, to make it effective, specific technological and teaching solutions must be implemented. The research revealed that companies' employees give preference to TEL than other forms of learning, and defined specific requirements for successful technology enhanced learning integration into business organisations. A theoretical literature review is followed by empirical findings of a qualitative research (focus group interviews) in two international IT companies. The findings of the research offer valuable insights for a responsive TEL integration into business organizations from the point of view of companies' employees.
\end{abstract}

Keywords: Technology enhanced learning (TEL), e-learning, business organization

\section{Introduction}

Technology enhanced learning (TEL) offers many advantages in terms of accessibility, usability, flexible timing and possibilities to re-use learning materials, but there is a number of aspects related to curriculum, content development and learner support systems that have to be adequately resolved in order to make TEL user-friendly in the corporate environment. Number of studies indicate (Mungania, 2003; Wolpers \& Grohmann, 2005; Admiraal \& Lockhorst, 2009; Hamburg \& Hall, 2013; Wu, 2013) that companies very often fail in implementing successful TEL integration within their organizations.

Obviously, enterprises increase the value of their human capital and business through continuous learning. However, enterprises and particularly small and medium-sized (SMEs) are extremely eager to have a rather fast return on the learning investment. If the effect is not visible and clear, managers as well as employees are not much motivated in learning activities. Alternatively, SMEs look for new learning and training tools and platforms which may help companies to achieve their learning needs. This approach, as noted by Admiraal and Lockhorst (2009), means that companies prefer informal and on-the-job training instead of formal and class-based training. On-the-job training (and learning) or training which is organized in companies environment (the so-called contextual learning) encompasses such important principles as training focused on real working life situation, interactive relation with trainers, instructors, possibilities to work in teams 
and solve problems, etc. Technology enhanced learning tries to incorporate these peculiarities and characteristics of SMEs learning and to offer the best solutions based on the following advantages (Admiraal \& Lockhorst, 2009):

- No space needed;

- Substantial cost savings due to the elimination of travel expenses;

- Timely access to information;

- Greater flexibility in the workplace, and

- Greater flexibility in addressing the learners' needs.

Nonetheless, technology enhanced learning despite many advantages, the list of which may be further elaborated, has not reached a very high level of integration within business organizations.

SMEs as well as other business organizations are very much inclined to foster informal learning culture. Through a variety of learning platforms and solutions TEL may easily respond to these learning characteristics. In this research paper we argue for a responsive strategy of TEL integration into business organisations, which is based on learners' needs (or user's) approach. This approach requires specific solutions, which are analysed and argued in this paper as the main prerequisites for a responsive TEL integration. Accordingly the key research question was formulated: what are the main enablers and barriers for TEL integration into business organisations. The following sub-questions were raised:

1. what are the main characteristics of a responsive integration of TEL into a business organisation;

2. what are particular advantages of TEL perceived by learners in business organisation;

3. what are the main disadvantages or problems of TEL.

\section{Challenges of responsible TEL integration in organizations}

The more remote/distant learning is in terms of teacher/learner relation, the more different teaching and technological decisions are to be made by those who plan and design a learning process. Simple social interactivity that may easily be achieved in a classroom environment because of eye-contact and emotional rapport is not so easy to be planned in distance e-learning, even in case of synchronous teacher-learner communication in a video connection, not to mention how difficult it is to create interactivity in an asynchronous distance learning. There is a need for different technological and teaching solutions and even more - a need for a different TEL integration paradigm in technology enhanced learning.

According to Fang (2001) our skill-based society has transformed to a knowledge-based society where human resources are valued for their abilities to solve real world problems. These skills are knowledge driven and thus need to be sharpened. Fang (2001) concludes that (1) user needs and user readiness would drive the means in technology, (2) learners are the centre of learning and teaching and their role is becoming increasing autonomous, (3) learning is no longer limited to subject-base but rather it is becoming more comprehensive, integrated, and lifelong.

However, using technologies in training is not solely related to challenges, but also to positive learner motivation and increased organizational morale. According to Van Merrienboer and Brand-Gruwel (2005) using blended learning tools increases learners' satisfaction. Besides, one of the major values of TEL according to Van Merrienboer and Brand-Gruwel (2005) is a possibility to use simulations in training as it very well relates to contemporary learning theories, emphasizes real life tasks and focuses on performance (Merrill, 2002). 
Technology enhanced learning has a lot of advantages, such as accessibility of materials from home, possibility to use convenient timing for learning or posting remarks, as well as possibility for deeper reflections in written when posting remarks on forum rather than participating in an oral discussion (Petrides, 2002). However, lack of interaction and feelings of isolation are often mentioned as disadvantages associated with distance learning (Blanco et al., 2011; Vonderwell, 2003). Social interaction among learners themselves and learners and their teacher has a huge motivating impact on the learner's morale and achievements. Social interaction allows giving and receiving direct feedback, exchange of ideas and reflection of one's own ideas. In conventional learning and in technology supported learning supporting learners' meta-cognitive activities like reflection and self-reflection through support and guidance may increase their performance and motivation (Means et al., 2009). According to Kirschner et al. (2006) providing support and guidance for novice learners during learning process leads to a more effective approach to learning. TEL may be successfully integrated into business organizations if considerable attention is paid to the design, organization and technical aspects that are important to learners. According to Blanco et al. (2011), a number of issues need to be solved to maximize a TEL experience in organizations:

- A safe learning environment. Learners need a safe environment where they are free to ask questions and contact a teacher and their learning peers.

- Easy to learn/use interfaces. Learners and education experts (Mok et al., 2006) among the main challenges to learners mention mental fatigue and lack of time. According to Govindasamy (2002) e-learning content should be designed and developed in smaller manageable chunks known as learning objects, small units of instruction that can be taken as stand-alone units of instruction even when it is not presented within a wider content. Due to the fact that learning objects are smaller fractions they have increased shareability, reusability and easier to follow mode.

- Feedback and/or guidance provision throughout the whole learning period. Feedback is meaningful when it is delivered close to the time the task is performed. Adequate teacher feedback in online courses helps students develop meta-cognitive skills. Additional support for novice learners is more effective than fully independent learning. The level of support can be reduced as the learner's level of expertise increases. Timely contact with learners gives them support and the learners, in their turn, appreciate teachers following their progress.

- Thoughtfully designed learning. A good design can structure the visual and interactive display of learning contexts and facilitate meta-cognition. This includes a flexible learning environment which can be used by learners with different learning styles. Different learning styles may be addressed by presenting material in multiple modes, such as text, visual and audio information. As learners often lack awareness of their own learning process, providing materials in different modes can help them find out which information presentation type is the most effective to them.

- Possibilities for self-assessment develop learners' meta-cognitive skills that increase their independence and learning autonomy. Continuous self-assessment leads to better learning results. Self-assessment may be used in different learning stages and may include computer-based quizzes, practical exercises, and peer-assessment.

- Cooperative learning. Cooperative learning has a positive impact on learning motivation. Different ways of cooperation like synchronous (chats) and conferences and asynchronous (discussion groups, forums) and encouraging small group tasks allows learners to feel more comfortable to ask, answer and otherwise contribute to the topic. According to Rovai (2007) online discussions are important for motivation of learners and also for building a community feeling among those in the course. 
- Time management has a positive contribution to time control, job satisfaction and health, and negatively affects stress. Specified goals of the course, highlighted important issues, estimation of time needed to deliver tasks, a course calendar help to increase learner time control. Progress tracking and monitoring strategies in an online course contribute to maintaining motivation, whereas deadlines in the calendar improve self-fulfilment of learners. In traditional learning environments learning pace monitoring comes more naturally as teacher meets students on a regular basis and is able to monitor their progress. However, in a virtual learning environment learners have to manage their learning pace and task performance. Adults tend to have better developed time management skills than their junior peers (Trueman \& Hartley, 1996) but lack of time is still a problem for adult learners as well.

- Keeping up motivation using different or all earlier mentioned techniques (creating a sense of community, recognizing learners' efforts, providing real case-study examples, etc.). Motivation is a complicated issue in distance education, as students feel more isolated and tend to lose motivation more easily.

These enablers indicated by different researchers are argued to be highly important for TEL integration to corporate business training environment as well.

\section{Peculiarities of TEL in companies}

TEL integration still remains an important issue for practitioners and researchers (Mungania, 2003; Wolpers \& Grohmann, 2005; Admiraal \& Lockhorst, 2009; Hamburg \& Hall, 2013). Studies show (Hamburg \& Hall, 2013; Wu, 2013) that a trainer-based and conventional training methods are still the most typical ways for professional development in companies, mainly SMEs. New media is not positively accepted mostly because of high investments on IT infrastructure, low trust in e-learning and other reasons. Training and learning culture is very much connected with the old rooted beliefs about the effectiveness of face-to-face training.

TEL integration is poorly accepted in the enterprises because of the so-called short-term learning strategy. European level studies (Farvaque et al., 2009) prove that the majority of SMEs in Europe lack a long-term learning strategy, which prevents them from using the most advanced learning platforms and tools. Mainly because of the lack of this long-term strategy enterprises are not inclined to perform regular competence and/or qualifications needs analysis. A number of researchers(Chang \& Guetl, 2007; Schneckenberg, 2010; Wu, 2013; Hamburg \& Hall, 2013), stress that, notwithstanding the type of an organization, there should be an organizational policy and strategy for TEL implementation (the so-called e-learning strategy)and a responsible department which might undertake the organization, implementation and evaluation of elearning.

Another barrier defined by researchers is linked to insufficient provision of the adequate training materials and software. Many products available are more elaborated according to the needs of big enterprises and universities. SMEs lack tailor-made products, which consequently make elearning not very attractive. Furthermore, cooperation between SMEs and technology or content developers and providers is not extensive, which does not allow improving situation in a substantial way. The above described barriers are more typical for SMEs, nonetheless, similar problems might be found even in bigger enterprises.

Quite an informative overview of barriers for TEL integration is made by Hamburg and Hall (2013). They note that previous studies examined barriers which make SMEs fail to apply e-learning or utilize the Web for effective continuous vocational education and training (CVET). These barriers may be grouped into several major categories: barriers related to IT infrastructure and provisions (such as a lack of relevant ICT applications; a lack of electronic content which can 
be found easily), barriers related to strategic approaches in learning and technology (a lack of understanding of all the advantages of e-Learning particularly by managers and a person responsible for further education in companies; a lack of staff motivation; a lack of time to explore TEL opportunities, etc.) and the so-called didactical barriers (a reactive approach to learning, a need for greater interactivity, instructor / tutor support, etc.).

Wu (2013) tried to explain problems in TEL integration from a slightly different perspective. From his point of view TEL integration is slow because of the lack of attention from the leadership (management) side. The researcher substantiates this argument from successful cases of enterprise e-learning projects. Motivation and human resources management policy factors are undoubtedly important. Wu (2013) suggests that if learning were closely combined with performance assessment, the motivation of employees for e-learning would definitely increase. Clearly defined learning outcomes and objectives are also very important. Many surveys on TEL integration problem point to the fact that many e-learning courses have no clear learning objectives, which de-motivate adult learners. Other didactical aspects such as the course based on real practical problems, support from instructors, interactivity, etc. in e-learning also should be taken into serious consideration.

IT infrastructure issues also play a significant role. This factor is relevant to almost any type of enterprises as it is related to ROI aspect. TEL will not be attractive in enterprises with no adequate level of ICT infrastructure. Thus, Wu (2013) stresses that e-learning or TEL requires a certain standard of hardware. This idea is clearly expressed by Admiraal and Lockhorst (2009), who analysed peculiarities of e-learning in small enterprises. Based on the research results Admiraal and Lockhorst (2009) state that "one major potential drawback of using e-learning in small firms is the technology infrastructure". TEL integration requires investment in both information technology and staff. The authors specify that enterprises should allocate funds to design and build a learning environment and actual courses as well as hardware and software costs to allow users to access the learning environment or training.

Computer literacy problems may become an important drawback for the integration of TEL into an organization. If employees do not master a high degree of information technologies, then the proficiency in computer and network restricts the way of e-learning (Wu, 2013). In order to overcome this barrier, enterprises should have a rather high computer literacy standard for their employees.

\section{Findings of empirical research}

\section{Design of empirical research}

The qualitative research on employees' experiences and needs for technology enhanced learning was performed in two international ICT companies based in Lithuania. The companies were chosen for their relatively similar profile: they are successful, growing, foreign capital companies competitive in IT business and belong to the category of small and middle-sized business. Focus group interview method was chosen because of its relevance trying to explore individual opinions on the integration of TEL in organizational learning. The research also sought to identify the main barriers and enablers while integrating TEL into business organizations.

The research sample of the informants was a targeted qualitative sample. Focus groups chosen by using a purposive sampling method ensured representation from experienced and newly qualified employees. Participants in this type of research are selected on the criteria that they would have something to say on the topic, are within the age-range, have similar socio-characteristics and would be comfortable talking to the interviewer and each other (Richardson \& Rabiee, 2001). The main criteria for participating in the focus groups was any kind of experience with TEL. 
From the total number of 188 participants, 83 of them were females and 105 males. According to the age groups the youngest employees who participated in the research were 18 , the oldest -60 years. Work experience of the companies' employees varied from several months to 19 years.

The research was supported by the companies, but informants' participation was on voluntary basis. They were informed about the goals of the research and principles of ethics, confidentiality and granted a verbal agreement to participate in the research. The total of 18 focus group interviews lasted for an average of 1 hour. The number of participants in each focus group varied from 5 to 15 participants, with the total number of 188 participants. Only 28 participants of the whole lot of 188 participants had no previous experience in any form of TEL. The researchers organized 10 focus groups in one company (total 72 employees participated) and 8 focus groups in the other (total 116 employees).

Based on the theoretical analysis on TEL integration into business organisations, the research tool was developed. It consisted of the following questions for discussion:

1. Have you ever participated in any TEL events?

2. Remember the training you liked most and tell:

a. Why this training was useful for your professional development?

b. Why this training was useful for improving your work efficiency?

3. Remember the training you disliked most and tell:

a. Why didn't you like the training?

b. Which aspects made you feel uncomfortable with the training?

4. How do you imagine a distance learning environment - describe its functionality, design, synchronization, collaborative tools.

5. How do you manage innovations in your company?

The interpretive content analysis was used to identify the main concepts, develop categories and sub-categories.

\section{Learner needs in TEL}

The research participants expressed a need for a safe learning environment which could help to use the best of TEL. A safe learning environment was conceived more like a restricted area for expressing one's learning needs and the learning process. The participants in 14 focus groups mentioned that it is useful
"to have an inner platform for expressing learning needs and for learning".
"We don't have such a system. Of course we would like to have one."
"It would be useful in meeting the needs of different people, including different training modules".

"It is a possibility to get acquainted with the culture of communication and other aspects".

According to the informants,

"people are different: one thing is important to one person while other things are important to the other". 
The participants of 16 focus groups emphasized user-friendliness of the learning platform: learning should be easily accessible through different learning devices, operational systems and training materials should have an easy interface and be rich in graphic pictograms. The participants also mentioned the possibility to pause while learning and later return and repeat if needed. The learning needs included different aspects:

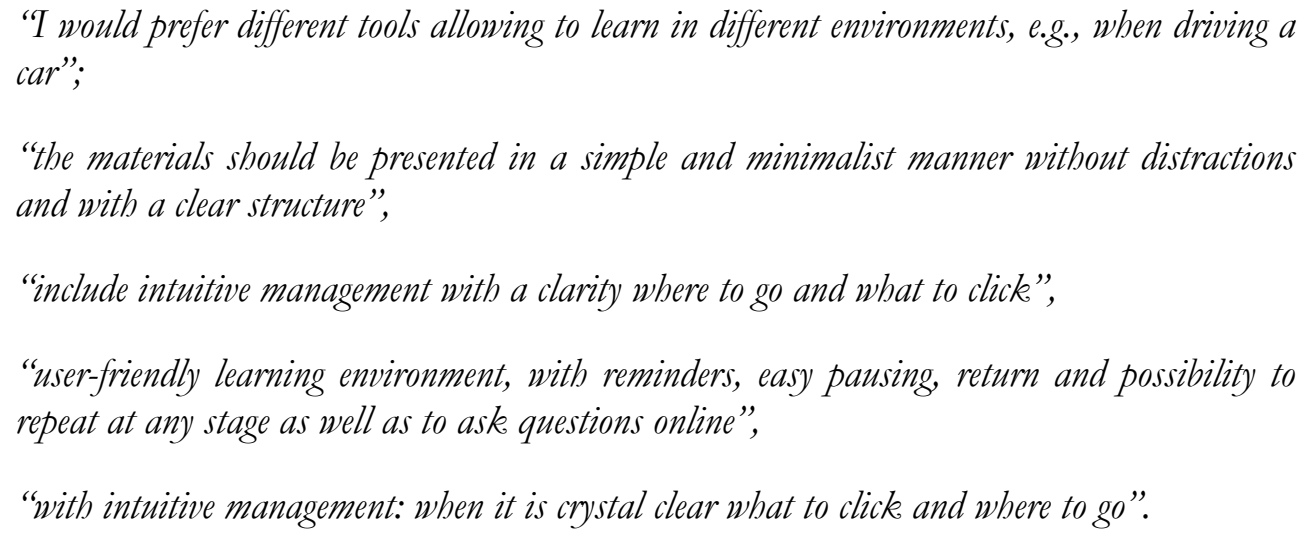

The training material should also be not complicated.

The participants of 14 focus groups expressed their need for different formats of material presentation: text, video and audio. The informants emphasized a need for

"explanatory illustrations, forms and schemes avoiding only pure text",

"explanations with illustrations, forms, and not just black and white text file",

so that the same

"information was presented in text, video and other formats",

teaching must be based on two principles

"simplicity and minimalism".

The participants wanted

"less theory and more practice",

"training differentiation into groups according to learning needs".

The theoretical survey suggests that feedback and/or guidance provision is crucial for a successful TEL. The informants mentioned that it is not motivating when

"you ask a question and do not receive an answer",

"to have a teacher available online on a certain time in order to ask for explanations".

The participants of one focus group also talked about possibilities for self-assessment as a motivating method during the training session.

The participants of 8 focus groups would prefer to use tools for cooperative learning: forums, chats, possibilities for synchronous discussions allowing direct communication with a teacher and other learners. The participants think that it is important to have 


\begin{abstract}
"a possibility to raise questions in synchronous and asynchronous ways",
"a possibility to discuss things that you do not understand in a chat or on a board with other participants",

"a possibility to see who else is also participating and communicate, so to see something more than the Powerpoint slides".
\end{abstract}

The participants of the focus group discussions consider that learning in their work place allows meeting their communication needs. However, they would prefer learning in smaller groups as group work is always most beneficial. They also mention the necessity to differentiate learners into groups according to their level of knowledge and achievements.

Time management was another aspect that the informants mentioned regarding TEL in their organizations.

"Learning 1 hour a day, the total of 5 hours a week is attractive, but achievable only in case of using TEL”.

The participants say:

"When I first encountered distance learning, what I enjoyed most was the fact that you could adjust learning to your own schedule, to listen and to read".

Different technological solutions may assist learning. Two discussion participants indicated the need for time management tools:

"a calendar to indicate the learning days for your own planning",

"you receive a calendar notification into your Outlook, you save it and see it in your daily schedule".

Even though some authors mention a motivating potential of TEL, the participants of the focus group discussions did not outline this aspect. However, the participants of the discussions indicated the important role of a teacher in TEL, which includes his/her personality, a preparation level for the training session, a teacher's qualification and competencies.

\title{
The main problems of poor TEL integration
}

Referring to integration of TEL and successful or unsuccessful training, the participants of the focus group commented on different teaching styles and teacher personalities. The answers described a negative attitude towards a teacher-centred training approach. The informants mentioned old-fashioned attitudes, unwillingness to change:

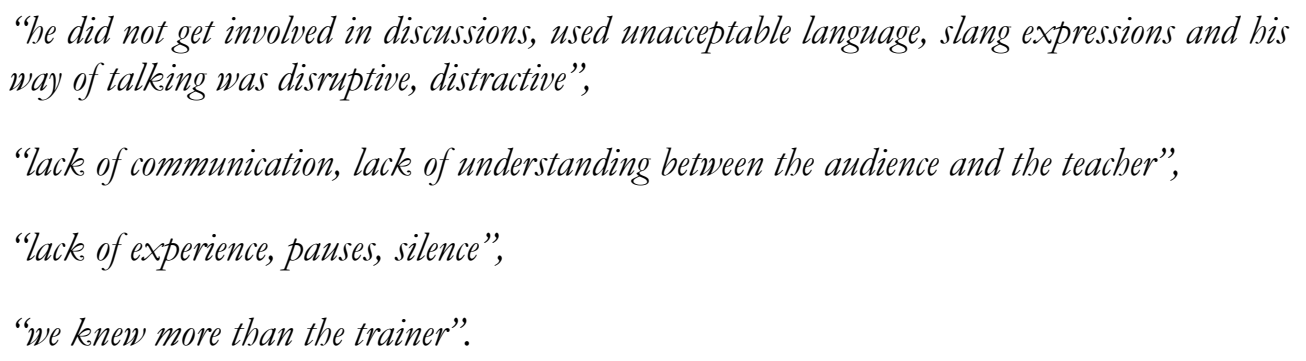

Other participants indicated that, on the other hand, for them the teaching subject was more important than the teacher: 
"The topic is in the first place, the lecturer is in the second".

Integration of TEL into organizations is not uncomplicated in most cases. Due to the fact that the participants of the research belonged to the ICT sector, they did not express their objections to the TEL, as an innovation. The employees were successful in using different technological solutions, the organizations had clear strategies for ICT upgrading:

"I try all innovations myself".

However, in one of the groups it was indicated that the employees were not fully aware of the company strategy, it was not clear from them why the training was organized for. In certain cases not all employees were aware of strategic organizational plans.

"Maybe we lack kind of consistency in our plans, how new technologies appear in our company. One could say we don't have any plan. No roadmat".

Even though both organizations work with technologies and create technological solutions, the employees feel a lack of adequate materials and software. They expect adequate training materials

$$
\begin{aligned}
& \text { it is not attractive "when you may google the same", } \\
& \text { "it is only useful if you learn how to use the knowledge in practice", } \\
& \text { "trainings about "the winds" }
\end{aligned}
$$

and an acceptable form:

$$
\begin{aligned}
& \text { "a too wide volume of material: too much text", } \\
& \text { "unprepared teaching tools", } \\
& \text { "you don't have to read yourself: you see a teacher and his slides besides". }
\end{aligned}
$$

As the main managerial barrier of integrating TEL, employees reproached, that the organizational training, ICT or TEL integration is usually implemented without investigating learning needs of the employees. Different trainings are organized, but sometimes they partly overlap, repeat and do not provide a maximized impact on the learners

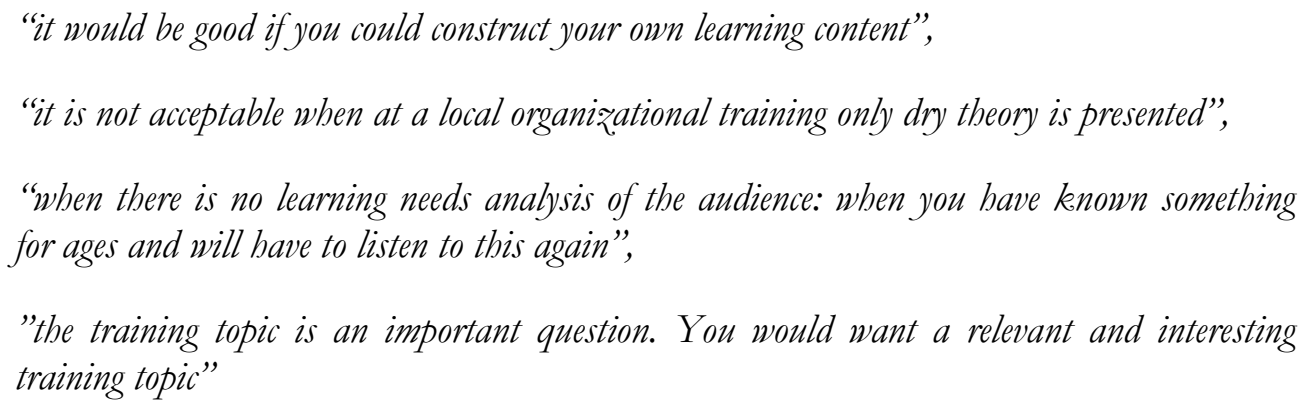

It would be useful to take into account the needs of different people and offer different training modules

"people are different: one thing is important for one person and the other for another. The choice would be individual". 
The mentioned TEL aspects are related to learners' performance and their learning motivation. When learning content and form is imposed on the learners, the relevance and attractiveness of the training content decreases. When motivation is missing, the relevance and importance of integrating TEL in the organization naturally decreases.

\section{Discussion and Conclusions}

The problems and barriers as well as the enablers of TEL in SMEs discussed in the article should be taken into consideration while developing comprehensive plans and strategies for TEL integration. Many e-learning strategies development approaches refer to Rogers' (2003) model for the diffusion and adoption of innovations (Schneckenberg, 2010). Davis (1989) characterises these approaches as innovation adoption models. Typically the innovation process starts from innovation development and is followed by dissemination, adoption, implementation, maintenance, sustainability, and institutionalization. It is also important to say that successful innovations are based on very important needs of clients and future users of the particular innovation. The empirical study revealed that on one side TEL can address the ambition to offer individualised training based on unique learning needs and learning objectives, on the other TEL can create a safe learning platform to communicate, to share and learn cooperatively. This can be achieved through different approaches. Learning environment should be user-friendly, accessible through different technological devices and serve as a restricted area for expressing learning needs and for learning about the needs of one's colleagues. In this case a safe learning environment can become useful for personal and professional development.

The current research findings prove that due to the fact that technologies are getting more widespread, question is no longer whether TEL should be used in organizational learning the question stays how well it is adapted to learner needs. Organizations very often organize trainings without a substantial analysis of learners' needs and, thus, decrease their motivation to learn. Similar results were described by Beer et al. (2008). A successful TEL integration is related to careful analysis and understanding of learning needs and objectives. According to these needs and objectives the learning content should be developed or adapted.

As the time factor is very crucial for enterprises, it should be appropriately matched with the form of training. One of the major advantages of TEL is mentioned to be a possibility to plan time. It means that TEL should ensure a learning continuity and strengthen a self-managed learning.

TEL is positively accepted by employees if they feel engaged. E-learning should be designed and mixed with other more traditional forms of learning. Interactivity is important, and support from instructors or tutors should come at the right time. The participants of the focus groups emphasized the variety of presentation of learning material, its interactivity, communication and cooperation with the teacher and the learners. However, a negative impact could be a teacher's personality and attitudes, being not prepared to deal with working adults, his/her inability to apply adult learning methods, choice of materials and methods, technological decisions, avoiding technological innovations.

Enterprises should also provide/develop the adequate learning infrastructure to support e-learning; this means that they should have a clear organizational perspective (strategy) on e-learning and knowledge transfer within and outside (through continuous learning in communities of practice, other learning platforms, etc.) an organization.

The results of empirical research showed that the major advantages of technology enhanced learning in business organizations could be named as a safe learning environment, easy to 
learn / use interfaces, thoughtfully designed learning, feedback and / or guidance provision, possibilities for self-assessment, cooperative learning, individual time management.

Such problems as a teacher-centred attitude, lack of long-term learning strategies, lack of adequate materials and software, managerial barriers for TEL, performance and motivation and IT infrastructure., inadequate materials, lack of motivation and failure to identify learning needs were identified as the major obstacles of technology enhanced learning integration into business organizations.

TEL integration into business organisations should be based on a responsive approach which means that strategic (eLearning strategy developed, learning needs and objectives identified and followed up), infrastructural (a safe learning environment developed, the adequate IT infrastructure provided) and quality assurance aspects (individualized and self-managed learning supported, a feedback provided, cooperative learning ensured, etc.) should be taken into consideration. Theoretical and empirical research results support this approach, which should form the framework for business organisations to develop different TEL integration models.

\section{References}

1. Admiraal, W. and Lockhorst, D. (2009). E-Learning in Small and Medium-sized Enterprises across Europe: Attitudes towards Technology, Learning and Training. In International Small Business Journal, 27(6), (pp. 743-767). doi:10.1177/0266242609344244.

2. Beer, D.; Busse, Th.; Hamburg, I.; Oehler, C. (eds.) (2008). Improving E-Learning Practices in SME. In Proceedings of the SIMPEL Final Conference in Brussels. April 14, 2008.

Universitas-Györ.

3. Blanco, M.M.; Van der Veer, G.; Benvenuti, L.; Kirschner, P.A. (2011).Design guidelines for self-assessment support for adult academic distance learning. Retrieved from:

http://www.academia.edu/2722249/Design_guidelines_for_self-

assessment_support_for_adult_academic_distance_learning

4. Chang, V. and Guetl, Ch. (2007). E-Learning Ecosystem (ELES) - A Holistic Approach for the Development of more Effective Learning Environment for Small-to-Medium Sized Enterprises (SMEs). In the Proceeding of Inaugural IEEE International Digital EcoSystems Technologies Conference (IEEE-DEST 2007), Cairns, Australia, (pp. 420-425).

5. Davis, F.D. (1989). Usefulness, perceived ease of use, and user acceptance of information technology. In MIS Quarterly, 13(3), (pp. 319-340).

6. Fang, W.M.Y. (2001).Technology in Language Education: Meeting the Challenges of Research and Practice. Hong Kong, Language Centre, HKUST, (pp. 94-105).

7. Farvaque, N.; Voss, E.; Lefebvre, M.; Schutze, K. (2009). Guide for Training in SMEs. European Commission.

8. Govindasamy, T. (2002). Successful Implementation of e-Learning Pedagogical Considerations. In Internet and Higher Education, 4(2002), (pp. 287-299). Pergamon. Retrieved from:

http://www.qou.edu/arabic/researchProgram/eLearningResearchs/successfulImplementati on.pdf

9. Hamburg, I. and Hall, T. (2013). Social Networks, Web and Mentoring Approaches in SME Continuing Vocational Education and Training. In Journal of Information Technology and Application in Education, 2(2), (pp. 85-94). Retrieved from: http://www.jitae.org/paperInfo.aspx?ID $=5232$ 
10. Hamburg, I. and O’Brien, E. (2013). E-Learning 2.0, Social Media and Communities to Improve Knowledge in Companies. In Service Science and Management Research (SSMR), 2(3), (pp. 33-38). Retrieved from: http://www.seipub.org/ssmr/paperInfo.aspx?ID=6720

11. Kirschner, P.A.; Sweller, J.; Clark, R.E. (2006). Why minimal guidance during instruction does not work: An analysis of the failure of constructivist, discovery, problem-based, experiential, and inquiry-based teaching. In Educational Psychologist, 41(2), (pp. 75-86).

12. Means, B.; Toyama, Y.; Murphy, R.; Bakia, M.; Jones, K. (2009). Evaluation of evidence based practices in online learning: A meta-analysis and review of online-learning studies. Washington, D.C.: US Department of Education.

13. Merrill, M.D. (2002). First principles of instruction. In Educational Technology, Research and Development, 50(3), (pp. 43-59).

14. Mok, M.M.C.; Lung, C.I.; Cheng, D.P.W.; Cheung, R.H.P.; Ng, M.L. (2006). Self-assessment in higher education: experience in using meta-cognitive approach in five case studies. In Assessment and Evaluation in Higher Education, 31(4), (pp. 415-433).

15. Mungania, P., (2003). The Seven e-Learning Barriers Facing Employees. Final Report. Retrieved from: http://www.academia.edu/8420360/The_7_E-Learning_Barriers_facing_Employees__Penina_Mungania

16. Petrides, L.A. (2002). Web-based technologies for distributed (or distance) learning: Creating learning-centered educational experiences in the higher education classroom. In International Journal of Instructional Media, 29(1), (pp. 69-77). Retrieved from:

http://www.iskme.org/sites/default/files/admin/web-based-technologies-for-distributed-ordistance-learning.pdf

17. Richardson, C.A. and Rabiee, F. (2001). 'A Question of Access' - an exploration of the factors influencing the health of young males aged 15-19 living in Corby and their use of health care services. In Health Education Journal, 60, (pp. 3-6).

18. Rogers, E.M. (2003). Diffusion of Innovations. (5th ed.) New York: Free Press.

19. Rosenberg, M.J. (2001). E-Learning. Strategies for delivering knowledge in the digital age. New York, NY:McGraw-Hill.

20. Rovai, A.P. (2007).Facilitating online discussions effectively. In Internet and Higher Education, 10, (pp. 77-88). doi:10.1016/j.iheduc.2006.10.001

21. Schneckenberg, D. (2010). Overcoming barriers for eLearning in universities_portfolio models for eCompetence development of faculty. In British Journal of Educational Technology, 41(6), (pp. 979-991). doi: 10.1111/j.1467-8535.2009.01046.x

22. Slotte, V. and Herbert, A. (2008). Engaging Workers in Simulation-based e-learning. Positive effects of simulation-based training. In Journal of Workplace Learning, 20(3), (pp. 165-180). doi: $10.1108 / 13665620810860477$

23. Trueman, M. and Hartley, J. (1996). A comparison between the time-management skills and academic performance of mature and traditional-entry university students. In Higher education, 32(2), (pp. 199-215). doi: 10.1007/BF00138396

24. Van Merrienboer, J.J.G. and Brand-Gruwel, S. (eds.) (2005). The Pedagogical Use of Information and Communication Technology in Education: A Dutch Perspective. In Computers in Human Behavior, 21, (pp. 407-215). Special issue.

25. Vonderwell, S. (2003). An examination of asynchronous communication experiences and perspectives of students in an online course: A case study. In Internet and Higher Education, 6, (pp. 77-90).

European Journal of Open, Distance and e-Learning - Vol. 17 / No. 2 
26. Wolpers, M. and Grohmann, G., (2005). PROLEARN: technology-enhanced learning and knowledge distribution for the corporate world. In International Journal of Knowledge and Learning, 1(1/2), (pp. 44-61). Retrieved from:

http://www.inderscience.com/info/inarticle.php?artid=6250

27. Wu, F. (2013). Development Research of E-learning in Chinese Enterprises. In the Proceedings of the International Conference on Educational Research and Sports Education (ERSE 2013), (pp. 262266). DOI: http://dx.doi.org/10.2991/erse.2013.75. Retrieved from: http://www.atlantispress.com/php/pub.php?publication=erse-13

\section{Acknowledgement}

The authors of this paper would like to acknowledge the Lithuanian Science Council and the European Social Fund which sponsored this work under the Global Grant measure (VP-1.3.1SMM-07-K-03-045). 